\title{
Aproximación al régimen local de Québec*
}

\author{
Antonio Calonge Velázquez \\ Profesor Titular de Derecho Administrativo \\ Universidad de Valladolid
}

«Sin instituciones municipales una nación puede otorgarse un gobierno libre, pero no posee el espíritu de la libertad»

Alexis de Tocqueville, La democracia en América, Orbis, Madrid, 1985.

Sumario: I. INTRODUCCIÓN. II. BREVE EVOLUCIÓN HISTÓRICA. 1. El régimen francés. 2. El régimen inglés. III. CONSTITUCIÓN E INSTITUCIONES MUNICIPALES. IV. FUENTES DEL DERECHO LOCAL. V. MUNICIPALIDADES: CONCEPTO Y CLASES. 1. Concepto. 2. Clases. VI. EL GOBIERNO LOCAL. 1. El gobierno de las municipalidades locales. 1.1. El consejo municipal. 1.2. El alcalde. 1.3. Otros órganos de gobierno. 2. El gobierno de las municipalidades regionales.

\section{INTRODUCCIÓN}

Parece ser una constante en muchos países la poca o escasa atención que los juristas prestamos al estudio del régimen local. Canadá no es una excepción a esta presunta regla general y, por ello, Rowat ha afirmado que «el estudio de los regímenes municipales ha sido descuidado» ${ }^{1} \mathrm{o}$, de manera más expresa, Bourassa ha llegado a manifestar -exagerando un poco, según sus propias palabras- que el sector municipal no está subdesarrollado, sino, al contrario, prácticamente sin explotar ${ }^{2}$.

Son muchas las causas, sin duda, que explican esta situación en Canadá y, quizás, la más fundamental sea la que dice que ha habido una preocupación por los gobiernos provinciales y federal en detrimento del régimen local, algo - por cierto- muy similar a lo que ha ocurrido en España desde la aparición de las Comunidades Autónomas, lo que ha motivado que la Administración local haya sido, como he escrito en otro lugar, la gran «olvidada» de la Constitución de $1978^{3}$ y, más amplia-

\footnotetext{
${ }^{*}$ El presente trabajo ha sido realizado con una beca del Ministerio de Asuntos Exteriores del Gobierno canadiense.

${ }^{1}$ Donald C. Rowat, «Le système municipal canadien», Le système politique du Canada, dir. $\mathrm{M}^{\mathrm{a}}$ Louis Sabourin, editions de l'Université d'Otawa, Otawa, 1970, p. 319.

2 Guy Bourassa, «Le système municipal québécois», op. cit., p. 337.

3 Antonio CAlonge VelázQuez, «La Administración municipal: la gran «olvidada»», La Constitución española de 1978 en su XXV aniversario, dirs.: Manuel Balado y J.A. García Regueiro, CIEPIICP- Bosch, Barcelona, 2003, pp. 741 y ss.
} 
mente, habría que decir que durante buen tiempo del régimen constitucional en general.

A poca atención que preste el viajero que llegue a Canadá y, más en concreto, a Québec, de inmediato se dará cuenta de encontrarse en un país muy variado, muy plural, desde muchos puntos de vista. Las razas, las lenguas, las religiones, las ideas políticas, los regímenes jurídicos, etc., han encontrado aparentemente su lugar de convivencia pacífica en esta parte del mundo.

Es oportuno hacer con carácter previo varias consideraciones. La primera es que hablar del régimen local de Canadá es una tarea prácticamente imposible, por la sencilla razón de que no existe un sistema municipal uniforme, sino que cada una de las Provincias que integran Canadá tienen competencias exclusivas, como veremos más adelante, para establecer sus instituciones municipales y, en consecuencia, hay tantos regímenes locales como Provincias existen en Canadá. Según tendremos ocasión de exponer, la misma Provincia de Québec carece de un régimen local uniforme y no sólo por la variedad de sus entidades locales, sino también porque dentro de estas categorías, los regímenes jurídicos son diferentes, aunque también es cierto que encontraremos elementos comunes y así, por ejemplo, descubriremos que todas las municipalidades están dirigidas por un consejo, más o menos numeroso, de miembros elegidos por sufragio universal, al frente del cual se sitúa un alcalde o un prefecto. Expuesto esto, más valdría que tituláramos el trabajo en plural, pues, además de ser jurídicamente más correcto, resulta más adecuado a la realidad que pretendemos exponer.

Como segunda consideración que estimo necesario realizar antes de iniciar la exposición de los regímenes municipales que se dan en Quebec es que sólo nos vamos a ocupar de los aspectos orgánicos dejando para otra ocasión el análisis de los aspectos funcionales o materiales, esto es, los asuntos a que se extienden las competencias de las entidades locales. El título del trabajo -recordémoslo- se inicia con el término «aproximación», esto es, nuestra intención es modesta, pues sólo pretendemos iniciar al lector en el apasionante mundo local de Quebec.

Finalmente -aunque volveremos sobre ello en un epígrafe posterior-, es preciso adelantar para que no exista equívoco alguno, que las muni-

\footnotetext{
${ }^{4}$ Las Provincias son: Québec, Hontario, Nuevo Brunswick, Nueva Escocia, Manitoba, ColumbiaBritánica, Isla del Príncipe Eduardo, Saskatchewan, Alberta y Terranova y Labrador, Territorio del Noroeste, Yukon y Nonavut. Las cuatro primeras agrupadas con la entrada en vigor de la Constitución o, mejor dicho, el Acta de América del Norte británica de 1 de julio de 1867 y las demás en el período comprendido entre 1870 y 1999.
} 
cipalidades a que nos vamos a referir, las entidades locales de Québec son sujetos de descentralización territorial que persiguen objetivos más políticos que administrativos, pero no lo son de autonomía. Es decir, se habla de entidades que no poseen poderes originales y autónomos, sino simplemente delegados, susceptibles de serles retirados por la Administración Federal o de Quebec ${ }^{5}$. Como veremos, la Constitución canadiense sólo se refiere a las instituciones municipales en una ocasión y para señalar que éstas pertenecen a la exclusiva competencia de las Provincias. Ello supone que carecen de base constitucional y, por tanto, no tienen asegurada su existencia y, mucho menos, un haz de competencias o poderes.

\section{BREVE EVOLUCIÓN HISTÓRICA}

Resulta conveniente que, antes de que demos cuenta del régimen local vigente en la Provincia de Quebec, volvamos la mirada atrás para conocer cómo han surgido y se han desarrollado sus instituciones municipales; en definitiva, que resumamos con brevedad la historia de Quebec adentrándonos en un camino impropio de quien esto escribe, pero que considero necesario para mejor informar al lector ${ }^{6}$.

Acostumbran los autores a hacer, cuando menos, una división del régimen municipal de Quebec en dos grandes épocas: la del régimen francés y la del régimen ingles?

\section{El régimen francés ${ }^{8}$}

Bajo el régimen francés es opinión común afirmar la práctica inexistencia de instituciones municipales. Durante esta época, que abarca desde 1608 (establecimiento de la primera colonia francesa, es decir, la fundación de Québec por Simon Champlain) hasta 1760 (capitulación de Qué-

\footnotetext{
${ }^{5}$ En este sentido, René Dussault y Louis Borgeat, Traité de Droit Administratif, $2^{\mathrm{a}}$ ed., T. I, Les presses de l’Université Laval, Québec, 1984, p. 208.

${ }^{6}$ Para una información completa y exhaustiva del régimen municipal en Québec, vid., Julien DRAPEAUX, Histoire du régime municipal au Québec, Ministère des affaires municipales, Québec, 1967.

7 Vid., por todos, André Tremblay y Reginald SAVoIE, Précis de Droit municipal, Wilson \& Lafleur, Montreal, 1973, pp. 16 y ss.

8 Vid., in totum, Gustave LANCTÔT, L'administration de la Nouvelle France, editions du jour, Montreal, 1971.
} 
bec después de la guerra de los siete años) $)^{9}$, no se conocen instituciones municipales permanentes y estables, aunque sí algunos intentos de establecimiento de una administración local, si bien en ningún caso deseados ni por los reyes ni sus gobiernos, como ha señalado L'HerEuX ${ }^{10}$, por la sencilla razón de que una administración centralizada de la colonia era menos costosa para la metrópoli que si hubieran existido entidades descentralizadas, esto es, más administraciones públicas en el vasto territorio de Nueva Francia.

De cuantos intentos de establecimiento de una administración municipal se han producido en la época colonial francesa merecen que destaquemos, al menos, dos:

El primero, es el que tuvo lugar el 20 de septiembre de 1663, fecha en la que el Consejo Soberano dictó una ordenanza autorizando la elección de un alcalde y dos échevins para la ciudad de Quebec. Estos cargos de la primera institución municipal fueron elegidos por una asamblea de ciudadanos de la ciudad en presencia del Consejo soberano. La existencia de este primer consejo municipal fue, sin embargo, bastante efímera, pues a los treinta y seis días de haber sido elegidos y sin que hubieran llevado a cabo actuación oficial alguna, el Consejo soberano decidió su supresión.

El segundo, tiene como artifice al Gobernador Frontenac, quien el 23 de marzo de 1673 dictó un reglamento estableciendo en Quebec un régimen municipal, pues decretó la elección de tres échevins para la ciudad, el primero de los cuales ejercería las funciones de juez de policía y los otros dos actuarían de adjuntos. Estos cargos serían elegidos por los ciudadanos por un período de un año, si bien su elección debería ser confirmada por el Gobernador. El primer échevin, según establecía el reglamento regulador de este consejo, tenía la facultad de convocar cada seis meses, con la autorización expresa del Gobernador, la asamblea de habitantes de la ciudad.

El reglamento del Gobernador Frontenac fue mal recibido en la metrópoli y Colbert -ministro de Luis XIV- escribió al autor del reglamento indicándole que se había extralimitado en sus funciones. Esta reacción del rey tuvo unos efectos inmediatos, pues los échevins ejercieron facultades

\footnotetext{
9 Vid., por todos, Diane SaINT-PIERre, L'evolution municipale du Québec. Un bilan historique, Union des Municipalités Regionales de Compté et des Municipalités Locales du Québec, Québec, 1994, p. 23.

10 Jacques L'Hereux, «Les premiéres institutions municipales au Québec ou "machines a taxer"», Les Cahiers de Droit, vol. 20, n. ${ }^{\circ} 1$ y 2, 1979, pp. 336 y 337.
} 
mucho más limitadas que las previstas para desaparecer poco después, y ser sustituidos por los síndicos, figura que ya había tenido una existencia en fechas anteriores y durante más de veinticinco años.

Desde el punto de vista de la organización territorial, la única división que se conoce en esta época dado la ausencia de administración municipal es la parroquia religiosa, que tendrá una importantísima incidencia en la aparición y desarrollo de las instituciones municipales de Quebec ${ }^{11}$.

En fin, durante el régimen francés, como vemos, la administración municipal era prácticamente inexistente. El Gobernador y, más en concreto, el intendente, que aparece en 1663 cuando la colonia es gobernada íntegramente por el rey, administra la colonia haciendo llegar el poder real de manera directa a todos los rincones de Nueva Francia.

\section{El régimen inglés}

En la segunda etapa, ya bajo el régimen inglés, las instituciones municipales irán apareciendo muy lentamente y en contra de los deseos, como más adelante explicaremos, de la mayor parte de la población canadiense francesa.

En virtud del Acta constitucional de 1791, Quebec se convierte en el Bajo Canadá junto con Hontario. Los sucesivos Gobernadores intentarán, entre 1763 y 1838, implantar instituciones municipales semejantes a las británicas existentes en el Alto Canadá ${ }^{12}$, pero sin éxito alguno. La Legislatura de Quebec será como un gran consejo municipal para toda el territorio, es decir, durante todo este tiempo la administración local del Bajo Canadá se asemejó a la que había habido bajo el régimen francés ${ }^{13}$.

Sin embargo, las ciudades de Quebec y Montreal constituirán una excepción a esta situación, pues en virtud de leyes especiales estarán gobernadas por sendos consejos municipales compuestos por un alcalde y veinte y dieciséis consejeros, respectivamente. Las cartas particulares de

\footnotetext{
11 Vid., sobre el particular, D. SaINT-PIERre, L'evolution municipale..., cit., pp. 30-37. También André Morel, «La municipalité, la paroisse et le Code civil du Québec», Revue Juridique et Politique, . $^{\circ} 2,1968$, pp. 661-672.

12 En 1793, el Alto Canadá votará «An Act to provide for the nomination and appointment of Parish and Town Officiers within the Province», que se aplica hasta 1842 y que permite a los ciudadanos elegir algunos cargos municipales encargados de representarlos y de ejecutar las leyes.
}

13 G. Bourassa, «Le système municipal...», cit., p. 339. 
estas ciudades fueron suspendidas a causa de las revueltas de 1836-1838 y no fueron repuestas sino hasta 1840.

En el medio rural, una ley preveía, desde 1818, que toda aldea de treinta casas habitadas en una superficie de 15 arpentes ${ }^{14}$ podía proceder a la elección de cinco síndicos, que tenían el poder de regular para el bienestar y la seguridad de su comunidad.

Después de las violentas revueltas de 1836-1838, que fueron duramente reprimidas por la Corona, el gobierno inglés envió a Ottawa a Lord George Lambton Durham, a la vez Gobernador general de las dos Provincias y como alto comisario real, con la finalidad de informar sobre la situación política en las colonias.

El célebre informe Durham, desde el punto de vista que nos interesa, denunciará la práctica inexistencia de administraciones locales en el Bajo Canadá. Cree que los problemas locales no pueden ser verdaderamente comprendidos y resueltos más que por autoridades locales. Estima, asimismo, que un régimen parlamentario verdaderamente eficaz requiere, en la base, un buen sistema de instituciones municipales. Propone, en consecuencia, que sean creadas dichas instituciones $y$, además, que sean reconocidas en la Constitución ${ }^{15}$. En fin, el informe a que nos estamos refiriendo se encuentra, sin duda, entre los orígenes de las instituciones municipales de Quebec ${ }^{16}$.

Los primeros resultados del informe Durham serán sendas leyes de 1840 adoptadas por el Consejo especial de Syndaham que pretendían instaurar las instituciones municipales en el Bajo Canadá. La primera, «Ordenance pour pouvoir á et regler l'élection et la nomination de certains officiers, dans les diferentes paroisses et townships de cette Province, et pour faire d'autres dispositions concernants les intérêts locaux des habitants de ces divisions de la Province», establece que toda parroquia religiosa o township existente que cuente con una población de, al menos, trescientos habitantes se constituirá en corporación municipal local, aunque con poderes muy limitados y con un consejo de gobierno que no está

\footnotetext{
14 El arpente es una medida antigua de superficie.

15 Los párrafos del informe referido en texto que más nos interesan pueden leerse en A. TREMBLAY, y R. SAvole, Précis de Droit..., cit., pp. 18-20. El informe completo, traducido, anotado y comentado puede verse en Hamel, Marcel-Pierre, Le rapport Durham, éditions de Québec. Québec, 1948.

16 Alain BAccigalupo, Les administrations municipales québécois. Des origines à nos jours, T. I, Les Municipalités, Éditions Agence d'ARC Inc, Ottawa, 1984, p. 119, ha conferido a Lord Durham el rango de padre fundador del sistema municipal quebequense.
} 
formado por personas elegidas, sino designadas. La segunda, «Ordenance qui pourvoit au mellieure gouvernement de cette province, en ettablisant des autorités locales et municipales en icelles», divide el territorio en distritos, creándose veintidós por una proclamación del Gobernador de 15 de abril de 1841. Cada distrito está administrado por un consejo que está compuesto por un gardien y cierto número de consejeros (dos o tres por parroquia o township que formen parte del distrito). El consejo puede dictar reglamentos para la construcción y reparación de edificios públicos, caminos, calles y puentes, imponer tasas, etc. Ahora bien, el Gobernador podía, oído el Consejo ejecutivo, no aprobar los reglamentos dictados por el consejo de distrito, así como disolverlo.

Ambas ordenanzas no fueron bien acogidas por la población por haber sido dictadas por el Consejo especial, producto de las revueltas señaladas, del que lógicamente desconfiaban, pues había venido a sustituir a la députation legítimamente elegida, así como porque el Acta de Unión del Alta y Bajo Canadá de 1841 -propuesta también en el informe Durham- recogió condiciones desfavorables para los canadienses franceses, esto es, los destinatarios de las ordenanzas mencionadas. Sin embargo, al decir de TREMBLAY y SAVOIE, ambas ordenanzas han constituido el verdadero fermento de las instituciones municipales que se conocen hoy ${ }^{17}$.

La legislación local de 1840 fue sustituida por una nueva Ley de 2 de marzo de 1845, llamada «Acte pour abroger certains ordenances et pour faire de mellieures dispositions pour l'etablissement d'autorités locales et municipales dans le Bas-Canada», que, además de derogar la legislación anterior, previó que todo territorio que contuviera, al menos, sesenta casas habitadas en una superficie que no excediera de treinta arpentes podría constituirse en aldeas o ciudades, formando sus habitantes una corporación municipal representada por un consejo, que no podía ser disuelto por el Gobernador, formado por siete consejeros elegidos por tres años. Un alcalde, designado por y entre los consejeros, preside dicho órgano, que dispone de competencias sobre los puentes y calzadas, la división de la municipalidad, el establecimiento de cercados públicos, la imposición de tasas de peaje sobre los puentes, etc., esto es, poderes más importantes y amplios que los que pertenecían a las corporaciones reguladas en la legislación anterior. La nueva ley, en fin, abolirá la anterior división en distritos y confirmará la división del territorio en parroquias, reconociendo, como ha afirmado L'HEREUX, exclusivamente corporaciones locales municipales ${ }^{18}$.

\footnotetext{
17 Op. cit., p. 21.

18 J. L'HereuX, Droit municipal québécois, T.I, éditions soreg, Montreal, 1981, p. 12.
} 
Las primeras instituciones municipales, según HÉTU y DuPLESSIS ${ }^{19}$, fueron creadas el 1 de julio de 1845, precisamente, por la Ley que acabamos de mencionar. Una proclamación de 18 de junio de 1945, publicada el 21 de junio en The Canada Gazette describirá cada una de las 321 municipalidades locales que fueron establecidas.

Ahora bien, esta ley tampoco será acogida satisfactoriamente por la población, siendo derogada diez años más tarde y sustituida por el «Acte des municipalités et des chemins du Bas-Canada» de 30 de mayo de 1855, que es, según ha expresado Saint-Pierre, «la base del régimen municipal actual $\gg^{20}$, pues contiene el principio de la doble organización -inspirada por Louis-Hippolyte Lafontaine- que se mantendrá durante más de un siglo con, por un lado, municipalidades locales y, de otro, municipalidades de condado. Esta ley, que vuelve a las municipalidades de parroquias y de townships, conservando las ciudades y aldeas y las municipalidades de condado, constituye, a juicio de L'Hereux, la base del actual sistema municipal quebequense ${ }^{21}$. La legislación de 1855 no se aplicará, sin embargo, a las ciudades de Québec, Montreal y Saint-Hyacinthe, que se constituirán en corporaciones municipales por leyes especiales.

La Asamblea Nacional de Québec, en 1870, dictará su primer Código municipal, sancionado el 24 de diciembre de 1879, que entró en vigor por proclamación el 2 de noviembre de 1871. Esta extensa norma, que regirá las municipalidades locales y las de condado, mantiene, como han manifestado TREMBLAY y SAVOIE, las «líneas maestras» ${ }^{22}$ de la legislación anterior aumentando los poderes de las municipalidades, pero sin dar respuesta a las necesidades de las grandes ciudades de Quebec, que verán satisfechas sus reivindicaciones en 1876 cuando el Parlamento quebequense apruebe el «Acte de clauses générales des coporations et villes, que, a partir de 1903, será denominada «Loi des cités et villes» y que será modificada sucesivamente (1925, 1941, 1964, 1970 entre otras) hasta llegar a la «Lois sur les cités et villes» vigente. Por su parte, el Código municipal actual se remonta a 1916, que introdujo importantes cambios en las competencias de las municipalidades locales, mientras que las municipalidades de condado, por el contrario, irán perdiendo sus facultades al asumirlas el Estado hasta que se produce su desaparición en 1979. El Códi-

\footnotetext{
19 J. Hetu y Y. Duplessis, Droit Municipal. Principes généraux et contentieux, Hébert Denault, Montreal, 1998, p. 3.

${ }^{20}$ L'evolution municipale..., cit., p. 49.

21 Droit municipale..., cit., p. 14.

22 Précis de Droit..., cit., p. 23.
} 
go municipal será modificado en numerosas ocasiones y refundido nuevamente en 1984.

A partir de aquí, pues, nos encontramos con una doble legislación para las municipalidades locales. Mientras el Código municipal será de aplicación, prácticamente, a las municipalidades rurales, la segunda ley será de aplicación preferente a las ciudades, esto es, delimitará claramente la frontera entre el mundo urbano y el rural.

De esta última época son también, debemos dejar constancia de ello, si bien sólo a efectos de mencionarlos únicamente, los organismos de control de las municipalidades: el ministerio de asuntos municipales, que se creó en 1918 y la Comisión nacional municipal, que se creó, como consecuencia de la crisis económica de los años 30, en 1932.

En resumen, el desarrollo del gobierno local de Quebec ha sido lento, pues, como han subrayado todos los autores, ha sido implantado con ausencia del apoyo popular, es decir, las instituciones municipales no han sido demandas por el pueblo, sino que le han sido impuestas ${ }^{23}$.

\section{CONSTITUCIÓN E INSTITUCIONES MUNICIPALES}

Si el epígrafe anterior nos parecía conveniente a efectos de ofrecer una mayor información del lector sobre el objeto central del presente trabajo, éste lo consideramos absolutamente imprescindible, pues, como dijera Otto Mayer, en la Constitución se encuentran cada una de las «tetes de chapitre» del Derecho administrativo y, en consecuencia, es necesario analizar qué establece el texto constitucional canadiense para conocer las raíces de las instituciones municipales quebequenses.

No es tampoco nuestra intención hacer una exposición exhaustiva del tema, ya que sería algo totalmente pretencioso por nuestra parte. La finalidad de este epígrafe es dar unas breves notas al lector de cómo están tratadas las instituciones municipales en la Constitución de Canadá ${ }^{24}$.

El Acta de América del Norte británica (AANB) o Constitución de 1867 sólo se refiere a las instituciones municipales en una ocasión, en concreto en el artículo 92, apartado $8^{\circ}$ para señalar que éstas son compe-

\footnotetext{
23 Vid., entre otros G. BourassA, «Le système municipal...», cit., p. 339.

24 Con mayor amplitud, vid. L'Hereux, Droit municipal..., cit., pp. 18-24.
} 
tencia exclusiva de las Provincias. El citado precepto constitucional reza de la siguiente manera:

«En cada Provincia, la Legislatura podrá establecer con carácter exclusivo leyes sobre las siguientes materias: ... Las instituciones municipales en las Provincias».

Señala, pues, el artículo transcrito que sólo las Provincias, con exclusión - prima facie- del Parlamento federal, puede crear o no instituciones municipales, así como conferirlas los poderes que consideren necesarios, siempre que sea dentro de su esfera de competencias.

La Constitución canadiense no garantiza, en consecuencia, la existencia de las instituciones municipales; no define las facultades de las municipalidades y, mucho menos, las dota de autonomía de ningún tipo; no prevé siquiera un régimen municipal. La autonomía municipal, han expresado con acierto Hétu y Duplessis, es un falso concepto en nuestro derecho $^{25}$.

Las municipalidades o, mejor dicho, las instituciones municipales para seguir la terminología constitucional, son creadas por las Provincias y sólo ellas pueden regularlas, controlarlas, suprimirlas, alterar sus límites, etc. Son, como ha indicado muy bien L'Hereux, «criaturas de las Provincias» ${ }^{26}$.

Esto que escribimos significa que las competencias que ostentan las entidades municipales no son propias, sino delegadas por la Provincia que las crea y se las confiere, por lo que, como hemos indicado al principio del trabajo, pueden serlas también retiradas por el mismo poder territorial que se las otorgó. Las municipalidades sólo pueden actuar, pues, en el marco de los poderes que le han sido delegados y, en virtud del conocido aforismo delegatus non potest delegare, no pueden subdelegarlos, salvo que la ley lo permita de manera expresa.

Las municipalidades, como ha afirmado el Juez Tellier en el caso Planeuf v. Corporation de Village de Saint-Hugues, no tienen más poderes que los que le han sido delegados. Ahora bien, los poderes delegados que ostentan las municipalidades no sólo procederán de la Provincia que las crea (Quebec, en nuestro caso), sino que también el Parlamento federal, como ha reiterado la jurisprudencia, tiene la posibilidad de delegar com-

25 Droit municipal..., cit., p. 10.

${ }^{26}$ Op. cit., p. 18. 
petencias en las entidades municipales, siempre que se haga con el consentimiento de la Provincia, y ello porque aquél tiene competencia para escoger las personas y organismos a los que confiar la ejecución de la ley.

El hecho de que hayamos predicado la competencia exclusiva de las Provincias sobre las institucionales municipales ${ }^{27}$, no significa la ausencia del Estado central en el gobierno de la materia local.

El Estado central interviene -y lo hace ampliamente- en el campo de lo local. De manera indirecta, ejerciendo las facultades que ostenta sobre materias que pertenecen a su exclusiva competencia y, de esta manera, al ejercer los poderes de que dispone sobre, por ejemplo, el transporte está produciendo ya importantes efectos en el campo municipal. Y, de manera directa, a través de la financiación y ayudas a las entidades locales para que se sumen a programas o actuaciones estatales, condicionándolas así al cumplimiento de normas estatales sobre el sector de la actividad subvencionada u objeto de ayuda y perdiendo, en consecuencia, las Provincias toda capacidad de control sobre las entidades locales en ese sector.

\section{FUENTES DEL DERECHO LOCAL}

Quizás el lector al retener en su memoria los últimos párrafos del epígrafe dedicado a la evolución histórica del régimen municipal de Québec ha podido obtener la impresión de que son dos grandes leyes las que constituyen las normas de aplicación a las entidades municipales quebequenses, según nos refiramos a municipalidades rurales o a municipalidades urbanas. A las primeras las sería de aplicación el Código municipal, mientras que las segundas estarían reguladas por la Loi sur les cité et villes. Pues bien, esa impresión del lector no sería, a mi juicio, ajustada a la realidad.

Resulta, pues, necesario, que demos cuenta de forma sumaria de cuáles son las fuentes del Derecho municipal, esto es, que enunciemos el extenso conjunto de normas que resultan de aplicación a las entidades municipales $^{28}$.

\footnotetext{
27 N. Pingeon, Cours de Droit Constitutionnel, texto mecanografiado, p. 195, ha dicho que el apartado 8 del artículo 92 de la Constitución de Canadá no se refiere más que a las estructuras municipales, estando contenidos en otros apartados del mismo precepto los poderes que las Provincias pueden otorgar a las entidades municipales.

${ }^{28}$ Para un conocimiento general de las fuentes del derecho canadiense, vid., A. TREMBLAY, Droit constitutionnel, les editions thémis, Montreal, 1993, pp. 5-29.
} 
En el vértice de la pirámide normativa nos encontramos, lógicamente, con las previsiones - escasísimas, como hemos visto- que contiene el Acta de América del Norte británica de 1867. Recordemos que sólo el artículo 92.8 tiene por objeto una referencia al régimen municipal.

A continuación, nos encontramos con las dos leyes generales ya citadas.

Por un lado, el Código municipal, que se aplica en todo el territorio de la Provincia, excepto en aquellas partes que se encuentran reguladas por una carta o ley especial y las que lo están por la otra ley general. Es la primera fuente de Derecho municipal.

De otro, la Loi sur les cités et villes, que se aplica a todos los territorios constituidos en ciudad desde el uno de enero de mil novecientos sesenta y nueve y, también, a todas aquellas constituidas en corporación por carta o ley especial. Sin embargo, no se aplica a las últimas municipalidades señaladas los preceptos de la ley general que sean incompatibles con lo dispuesto en la carta o ley especial, ni a las ciudades que fueron creadas conforme al antiguo Código municipal. Esta Ley es la primera fuente municipal para las ciudades.

También constituyen fuente primaria del Derecho municipal, sin ninguna duda, las cartas y leyes especiales que rigen las más de trescientas municipalidades de Quebec y que constituyen verdaderas singularidades a un posible Derecho municipal quebequense. La existencia de tantas singularidades o especialidades es lo que, entre otras razones, nos ha llevado a afirmar al inicio de este trabajo que no es posible hablar de un régimen local de Québec, sino que más correcto, desde el punto de vista jurídico y, sobre todo, más ajustado a la realidad es utilizar la expresión regímenes locales para expresar la variedad de normas que resultan de aplicación a las distintas clases de entidades municipales. Quebec y Montreal, las dos grandes ciudades de la Provincia, en razón de su importancia, han obtenido de la Asamblea Nacional sendas leyes específicas adaptadas a sus necesidades que contienen numerosas cláusulas exorbitantes de la ley general.

Los reglamentos y resoluciones dictados por los consejos que gobiernan las municipalidades de Quebec, el Código civil y el Código de procedimiento civil, así como otras leyes, tales como las de fiscalidad municipal, ordenación del territorio y urbanismo, organización territorial municipal, elecciones y referendums en las municipalidades y un buen número de leyes por razón de la materia, son, asimismo, fuentes municipales del Derecho municipal. 
Por su parte, fuentes secundarias son la jurisprudencia, el common law y la doctrina científica quebequense, primero y canadiense o británica, después.

En fin, todo este abigarrado y complejo conjunto de instrumentos normativos constituyen las disposiciones aplicables en la vida local de Quebec.

\section{MUNICIPALIDADES: CONCEPTO Y CLASES}

\section{Concepto}

El término municipalidad hacía referencia, a tenor de la legislación local quebequense, al territorio de la entidad local exclusivamente. En efecto, el artículo 16.1 del Código municipal definió la municipalidad como «el territorio constituido para los fines de administración municipal»; la Loi sur les cités et villes, por su parte, la definió, en su artículo 17.1, como «el territorio determinado por la carta que la crea»; y, finalmente, el artículo 1.5 de la Ley de organización territorial de 1964 también confirmó que la municipalidad se identificaba con el territorio cuando estableció que «La Provincia de Québec está dividida... para los fines municipales en municipalidades de cités y villes constituidas por ley especial o carta, y en setenta y tres municipalidades de condados, que están divididas en municipalidades locales, conforme al Código municipal». Estábamos, pues, en presencia, como ha escrito Baccigalupo, ante un concepto geográfico ${ }^{29}$.

Ahora bien, es verdad, como denunciara L'HeREuX ${ }^{30}$, que muchas veces se utilizó el término municipalidad no sólo en el sentido indicado por el legislador local, sino también queriendo expresar con él el cuerpo político de la entidad local, el cual se correspondía con la expresión corporación municipal. El legislador mismo y la doctrina científica también han venido utilizando indistintamente el término municipalidad para referirse tanto al territorio como al cuerpo político, esto es, a la entidad local entera.

Pues bien, este último es el sentido actual y vigente del término municipalidad. La municipalidad es una entidad administrativa que tiene existencia propia y que está habilitada por el gobierno provincial para ejercer,

\footnotetext{
29 A. Baccigalupo, Les administrations municipale..., cit., p. 172.

30 Droit municipal..., cit., p. 34.
} 
en un territorio determinado, las competencias que le son conferidas por la ley.

\section{Clases}

Siempre que un autor se enfrenta a una clasificación hay diversos criterios válidos para realizar la operación que pretende $\mathrm{y}$, por ello, puede afirmarse que cualquier clasificación es correcta siempre que se expliquen de manera suficiente y coherente los criterios de clasificación seguidos.

Podríamos, por ejemplo, clasificar las municipalidades de Quebec atendiendo a la legislación que las resulta aplicable y, así, distinguiríamos entre aquellas que se rigen por el Código municipal y aquellas otras que están reguladas por la Loi sur les cité et villes. En el primer grupo incluiríamos las municipales rurales y las municipalidades de villages y en el segundo a las ciudades o, también podríamos decir, municipalidades urbanas. Ahora bien, debe advertirse que esta distinción está en trance de desaparecer porque el Código municipal da los mismos poderes a las municipales que los que otorga la Loi sur les cités et villes a las ciudades. Además, tendríamos que incluir un tercer grupo de municipalidades que agrupara las villages nórdicas, las villages de cris y naskapi que se rigen, primordialmente, por una legislación específica y, también, a las municipalidades regionales de condado, las comunidades urbanas y la Administración regional de Kativik, que tienen sus leyes particulares.

Ahora bien, si empleamos el término municipalidad en el sentido propio y, ciertamente -en mi opinión-, restringido que lo dio el legislador local, más apropiado parece clasificar las municipalidades en dos grandes grupos que tienen presente el territorio que las conforman: las municipalidades locales y las municipalidades regionales. Las primeras constituyen el primer nivel de organización municipal, mientras que las segundas son estructuras supramunicipales o de segundo nivel. Veámoslas.

Las municipalidades locales agrupan a las municipalidades de campo, también denominadas rurales, las municipalidades de villages, las ciudades y las villages nórdicas, de cris y de naskapi.

Los términos municipalidades rurales y las municipalidades de village, como ha señalado Baccigalupo ${ }^{31}$, inducen a confusión por ser demasiados generales. Las villages son, en el lenguaje común, zonas rurales, por lo

31 Op. cit., p. 164. 
que unas y otras vendrían a ser lo mismo, aunque no así para el legislador quebequense. Su territorio es, como regla general, bastante restringido.

Las municipalidades de campo o rurales se dividen en cuatro categorías, a saber: parroquias, que no tienen que ver con las parroquias religiosas, aunque ese haya sido su origen; cantones, cantones unidos y territorios no organizados. Para constituirse en municipalidad rural es suficiente que el territorio de que se trate cuente con una población mínima de 300 habitantes, salvo en el lado norte del San Lorenzo entre Betsiamites y BlanSablon donde es suficiente una población de 100 personas.

Las municipalidades de villages, por su parte, requieren para constituirse tener, al menos, cuarenta casas habitadas con una población que no tiene porqué superar necesariamente los 300 habitantes en una superficie de 60 arpentes. Además, los inmuebles sujetos a imposición en este territorio deben tener como mínimo un valor de 50.000 dólares.

Ahora bien, desde el 1 de enero de 1989 estos requisitos para constituir municipalidad ya no existen y el gobierno provincial puede constituir una municipalidad en cualquier territorio en que se encuentren 300 personas o más, salvo circunstancias excepcionales.

Las municipalidades rurales y las de villages tienen todas, como veremos más adelante, la misma organización y los mismos poderes.

Las ciudades, reguladas en la Loi sur les cités et villes, están integradas por, al menos, 2000 habitantes, si bien, no es un requisito o condición automática que determine el paso de municipalidad rural o de village a ciudad, pues es el gobierno quien, conforme -incluso- a criterios de oportunidad, determina que una municipalidad rural o de village se constituya en municipalidad de ciudad. Es necesario que precisemos que la Loi sur les cités et villes, desde la reforma de 1968, no distingue entre unas y otras o, mejor expresado, el término cité desapareció, prevaleciendo el de ville, esto es, ciudad. La ley no prevé más que la constitución de villes. Solamente dos municipalidades tienen aún la designación de cité, que ostentan los mismos poderes, no obstante, que las ciudades. Quebec y Montreal, por su parte, están reguladas, como hemos adelantado con anterioridad, por sendas leyes especiales.

También en esta primera clase de municipalidades, las locales, deben incluirse los territorios autóctonos, esto es, los que están situados al norte del paralelo 55. Me refiero a las villages nórdicas, reguladas por la Loi sur les villages nordiques et l'Administration régionale Kativik y las villages cris y naskapi, regidas por la Loi sur les villages cris y le village naskapi. 
El segundo nivel de organización territorial local comprende las municipalidades regionales de condado, las comunidades urbanas y la Administración regional de Kativik.

El escalón regional es una estructura creada para hacer frente a los problemas intermunicipales. Las razones de ser de este nivel administrativo son, sobre todo, las que tienen por objeto estudiar las cuestiones que afectan al conjunto del territorio, integrar las diferentes soluciones de ordenación del territorio y preparar y ejecutar un plan para el territorio de la municipalidad. Todas las municipalidades regionales disponen de poderes que están unidos a su naturaleza esencialmente regional. Veámoslas.

La Loi sur l'aménegement et l'urbanisme de 1979 creó las municipalidades regionales locales, que sustituyeron a las municipalidades de condado $^{32}$.

Las municipalidades regionales de condado son organismos regionales que agrupan a todas las municipalidades de un territorio determinado, ya sean de carácter rural o urbano o, incluso, si se trata de un territorio no organizado. No son gobiernos regionales; ni siquiera puede verse en ellas una manifestación del principio de descentralización, pues aunque sus funciones no se limiten a la mera ejecución de las normas dictadas por la Provincia, carecen de poder normativo, así como de la capacidad de establecer impuestos ${ }^{33}$.

${ }^{32}$ Las municipalidades de condado estaban formadas por municipalidades rurales, de villages y territorios no organizados, pero no por territorios a los que resultaba de aplicación la Loi sur les cités et villes ni a las ciudades de Québec y Montreal.

Sus orígenes los encontramos en la división que se hizo del territorio de Québec en distritos electorales, aunque después sus límites nada tuvieron que ver con los de éstos. Las municipalidades de condado respondían, más bien, al principio de la doble organización que estableció la legislación de 1855 necesaria para conciliar las costumbres de los canadienses franceses con las británicas.

Estaban reguladas, al igual que las municipalidades rurales y de village, por el Código municipal. No obstante, entre unas u otras las diferencias eran importantes. El territorio de la municipalidad de condado era mucho más extenso que el de las rurales y de village, pues, estaba integrado por el de éstas; asimismo, el territorio de la municipalidad de condado estaba delimitado por una ley de la Asamblea Nacional, mientras que el de las municipalidades rurales y de village lo está por la proclamación del lugarteniente gobernador en consejo. También se diferenciaban en cuanto a los órganos de gobierno, pues los de las municipalidades de condado, en cuanto entidades de segundo grado, estaban integrados por los elegidos de las municipalidades rurales y de village, mientras que los de éstas están integrados por elegidos directamente por la población, como tendremos ocasión de ver.

Las municipalidades de condado fueron perdiendo importancia progresivamente, sobre todo, porque la Provincia se fue apropiando de lo que constituía su esfera de competencias.

${ }^{33}$ Más extensamente sobre este tipo de entidades locales, vid., A. Baccigalupo, Les administrations municipales..., cit., T. II, L'environement, pp. 662-716. 
Este tipo de entidades locales tienen como principal tarea elaborar y aprobar las directrices de ordenación del territorio, así como asegurar que los planes y reglamentos urbanísticos dictados por las municipalidades que formen parte de su territorio sean adecuados a las citadas directrices.

Las comunidades urbanas son entidades descentralizadas integradas por las municipalidades que forman parte de su territorio que apuntan a la regionalización de algunos servicios locales. Cada comunidad urbana está regulada por una ley particular, pues no existe ley general sobre este tipo de municipalidades.

Las comunidades urbanas existentes son las de Montreal, que agrupa a 29 municipalidades y cuenta con una superficie de $500 \mathrm{~km}^{2}$; Québec, formada por 13 municipalidades locales situadas en la rivera norte de la región metropolitana de Québec, de Saint-Augustin-de-Desmeures a Beauport; y Outaouais, desde 1 de enero de 1991, fecha de entrada en vigor de la Loi modifiant divers dispositions legislatives concernant les organismes intermunicipaux de l'Outaouais (con anterioridad era la Comunidad regional de Outaouais), que comprende el territorio de las ciudades de Aylmer, Buckingham, Gatineau, Hull y Masson.

El concepto de comunidad urbana, como han escrito TREMBLAY y $\mathrm{SAVOIE}^{34}$, no tiene por objeto ninguna idea de fusión de municipalidades y supresión de sus órganos de gobierno. Las comunidades urbanas reúnen a las ciudades y su periferia en una nueva organización local, que constituye una originalidad en el plano institucional inspirada a la vez en el federalismo y en el confederalismo ${ }^{35}$.

La Administración regional de Kativik agrupa las municipalidades de las villages nórdicas, el de la municipalidad de village de naskapi y un territorio no organizado. Esta municipalidad se constituyó tras la promulgación en diciembre de 1979 de la Loi sur les villages nordiques et l'Administration régionale Kativik. Es una entidad descentralizada que fue creada como consecuencia del estatuto especial de las villages nórdicas y de naskapi.

Quebec, en fin, cuenta con 1433 municipalidades locales, la mayor parte rurales y que cuentan con una población inferior a los 2000 habitantes. En el nivel supramunicipal, está dividido en 96 municipalidades regionales de condado, 3 comunidades urbanas y la Administración regional Kativik.

34 Op. cit., p. 66.

35 A. Baccigalupo, op. cit., p. 124. 


\section{CORPORACIONES MUNICIPALES: EL GOBIERNO LOCAL}

Si el término municipalidad era para el legislador local sinónimo de territorio, el de corporación municipal hacía referencia siempre al conjunto de habitantes y contribuyentes de una municipalidad. Los artículos 4 del Código municipal y 25 y 28 de la Loi sur les cités et villes lo definían como «el cuerpo político formado por los habitantes y los contribuyentes de una municipalidad». Si la municipalidad era un concepto geográfico, éste, en opinión también de BACCIGALUPO ${ }^{36}$, lo era jurídico y político.

La corporación municipal es una persona jurídica distinta de los miembros que la integran, a tenor de lo dispuesto en el artículo 352 del Código civil, y una institución jurídica creada por el Estado, en virtud de una decisión pública, regulada, principalmente, por el Derecho público y, supletoriamente, por el Derecho civil.

Sus poderes, que sólo pueden ser ejercidos en el territorio propio como regla general, son muy amplios, si bien son exclusivamente los que le ha conferido la ley. Así, las corporaciones municipales tienen, entre otras, la facultad de comprar y vender, contraer obligaciones e imponerlas dentro de sus atribuciones, prestar un gran número de servicios públicos, regular diversos aspectos de la vida comunitaria para asegurar la paz y el orden, el bienestar general y la mejora de la corporación.

Pues bien, las corporaciones municipales se expresan a través de los órganos de gobierno que las conforman.

\section{El gobierno de las municipalidades locales}

Las municipalidades locales, que están todas organizadas de la misma manera, se hallan gobernadas por un consejo municipal compuesto por personas elegidas por los habitantes de la municipalidad y un alcalde, asimismo, elegido de manera directa por todos los electores de la municipalidad. Así, pues, consejo municipal y alcalde son los órganos de gobierno de las municipalidades locales.

${ }^{36}$ Ibidem, p. 172. 


\subsection{El consejo municipal}

El consejo municipal es la cámara deliberante y de decisión de la municipalidad. Es el órgano que adopta los acuerdos acerca de las orientaciones y acciones generales de la municipalidad, quien la administra y, también, quien la representa. Su papel es asegurar que los servicios que presta la municipalidad respondan a las necesidades de los vecinos. Su principal responsabilidad es, pues, servir a los intereses de los ciudadanos. El artículo 47 de la Loi sur les cités et villes precisa que «la municipalidad está representada y sus asuntos son administrados por su consejo». De similar tenor es el artículo 79 del Código municipal.

Al consejo municipal, a la luz de lo dispuesto en los textos jurídicos, le corresponden, entre otras, las funciones siguientes:

a) establecer las políticas generales de la administración municipal

b) adoptar todas las decisiones relativas a la administración de la municipalidad

c) dictar reglamentos y resoluciones

d) aprobar el presupuesto anual y fijar los impuestos

e) aprobar los préstamos y obligaciones.

El consejo municipal está formado, en principio, por el alcalde y seis consejeros. La mayoría de las municipalidades locales tienen un consejo con esta composición. Si el territorio de la municipalidad está dividido en distritos electorales, el consejo municipal se compone de un consejero por distrito electoral ${ }^{37}$, además del alcalde. Las ciudades de Quebec y Montreal cuentan con sendos consejos municipales compuestos por el alcalde

\footnotetext{
${ }^{37}$ El número de distritos electorales en una municipalidad, según el artículo 9 de la Loi sur les élections et les referéndum dans les municipalités, es:

$1^{\circ}$ de al menos 6 y no más de 8 para una municipalidad de menos de 20.000 habitantes.

$2^{\circ}$ de al menos 8 y no más de 12 para una municipalidad de más de 20.000 habitantes y menos de 50.000 .

$3^{\circ}$ de al menos 10 y no más de 16 para una municipalidad de más de 50.000 habitantes y menos de 100.000 .

$4^{\mathrm{o}}$ de al menos 14 y no más de 24 para una municipalidad de más de 100.000 habitantes y menos de 250.000 .

$5^{\circ}$ de al menos 18 y no más de 36 para una municipalidad de más de 250.000 habitantes y menos de 500.000 .

$6^{\circ}$ de al menos 30 y no más de 90 para una municipalidad de 500.000 habitantes o más.
} 
y 39 y 73 consejeros, respectivamente, de acuerdo con lo que establecen las cartas que las regulan.

Los consejeros son elegidos por todos los electores de la municipalidad, salvo que ésta se halle dividida en distritos electorales, en cuyo caso lo serán cada uno por los electores de éstos.

La duración del mandato de los consejeros es de dos años, excepto que por reglamento de la municipalidad, que necesita de la aprobación del ministerio de asuntos municipales, se haya decidido que para el futuro el mandato de los consejeros sea de tres o cuatro años. El consejo municipal de las ciudades tiene, sin embargo, un período de mandato de cuatro años establecido de manera expresa por la ley.

El mandato da comienzo con el juramento de oficio y finaliza con el inicio de la primera sesión del consejo que se celebre después de las elecciones, en el caso de las municipalidades rurales y de village, y el día de la presentación de las candidaturas para la elección de los cargos municipales, en el caso de las ciudades.

\subsection{El alcalde}

El alcalde es el jefe del consejo municipal, quien lo preside y dirige. Es el órgano ejecutivo por excelencia de la municipalidad y, en consecuencia, al que corresponde el ejercicio de toda suerte de funciones administrativas. El alcalde tiene la facultad de vigilar, inspeccionar y controlar el funcionamiento de todas las dependencias y servicios municipales. Debe velar de manera especial porque los ingresos y gastos de la municipalidad se realicen conforme a lo establecido en las leyes. Ostenta el poder de formular propuestas al consejo municipal. Y, finalmente, dispone del privilegio de ejercer un derecho de veto sobre las decisiones o acuerdos del consejo, si bien se trata de un poder transitorio, pues el consejo puede levantarlo acordando con posterioridad el mismo reglamento o resolución objeto de veto.

En resumen, el alcalde:

a) ejerce la vigilancia, inspección y control de todos los departamentos y empleados de la municipalidad.

b) ejecuta la ley

c) propone nuevos proyectos al consejo 
d) vela por el estricto cumplimiento del ordenamiento jurídico en materia de finanzas locales

e) tiene el poder de vetar las decisiones del consejo municipal, aunque sea de manera transitoria.

La importancia de la función del alcalde lo asemeja, a juicio de Pierre ME VIAU, al modelo americano de «strong mayor and council system» ${ }^{38}$. Nosotros diríamos que el sistema de gobierno municipal quebequense es acusadamente presidencialista, aunque la letra de la ley disponga otra $\operatorname{cosa}^{39}$.

\subsection{Otros órganos de gobierno}

Además de los órganos de gobierno municipal a que se acaba de aludir deben ser también mencionados, siquiera sea con la brevedad requerida para un trabajo que sólo tiene la intención de acercar al lector al régimen local de Quebec, a otros dos órganos que forman parte de la organización municipal de todas las ciudades: las comisiones del consejo y el comité ejecutivo.

Las primeras, permanentes o especiales, son órganos creados para la vigilancia de la gestión municipal. Están presididas por el alcalde y compuestas por el número de consejeros que se considere adecuado.

El comité ejecutivo lo preside el alcalde y está formado por 3 ó 5 miembros designados por el consejo municipal, entre sus componentes, según que éste se componga de 12 a 20 consejeros o de más de 20 consejeros. Con un mandato de un año, tiene la función de preparar y someter al consejo los proyectos de reglamentos, el presupuesto anual, toda petición de préstamos o de cualquier otro crédito, etc. Este órgano rinde cuenta de sus trabajos al consejo municipal y sus decisiones no pueden producir efectos hasta que no hayan sido ratificadas por éste.

\section{El gobierno de las municipalidades regionales}

El segundo nivel de organización territorial, el supramunicipal o regional, está también gobernado por un consejo y un órgano unipersonal que

\footnotetext{
38 Pierre Me VIAU, «Atelier sur le statut du maire et des elus du peuple», UQM, Congrés, 1976, pp. 33-36.

39 A. Baccigalupo, Les administrations municipales..., cit., pp. 221 y ss.
} 
lo preside. La estructura y el funcionamiento de las municipalidades regionales, aunque no son iguales, se asientan, no obstante, sobre los mismo principios.

Las municipalidades regionales de condado cuentan con un consejo que tiene un funcionamiento y unas estructuras fijas, al frente del cual está el prefecto. Esto es, consejo y prefecto son los órganos de gobierno y administración de este tipo de entidades locales.

El consejo está compuesto obligatoriamente por los alcaldes de las municipalidades miembros y también puede estarlo por uno o varios representantes suplementarios, según la representatividad acordada a cada municipalidad en la carta de creación. Estos representantes suplementarios son designados por el consejo municipal respectivo de entre sus miembros. Los consejeros no tienen fijado período alguno de mandato, pero sí deben estar unidos a la condición por la que han sido designados miembros del consejo de la municipalidad regional de condado para permanecer en el cargo de consejero regional.

A la cabeza del consejo se encuentra el prefecto, elegido por los miembros del órgano entre los que ostentan la condición de alcalde. El prefecto es elegido por mayoría absoluta de los miembros que componen el consejo, salvo que la carta de creación disponga otra cosa, y para un período de dos años. Preside las sesiones del órgano colegiado y tiene voto de calidad en caso de empate. Un prefecto suplente es igualmente elegido entre los alcaldes para cumplir las funciones del titular del cargo en caso de ausencia o vacante de éste.

El consejo debe reunirse en sesión ordinaria, al menos, una vez cada dos meses. Cada miembro del consejo dispone de un voto, salvo que la carta de creación haya acordado, en función de la población de cada municipalidad, un número de votos distinto. El quórum de constitución del consejo está formado por un tercio de sus miembros que representen como mínimo la mitad de los votos. Las decisiones se adoptan por mayoría simple.

Las comunidades urbanas tienen también una organización similar a la que venimos describiendo, es decir, cuentan con un órgano colegiado y otro unipersonal: consejo y presidente.

El consejo de la comunidad urbana de Quebec está formado por los alcaldes de las trece municipalidades que la integran, de un sustituto permanente para la ciudad de Québec, así como por el alcalde de Boischatel, pero éste sólo cuando se trata de asuntos de transporte colectivo. Las deci- 
siones se toman con el acuerdo de, al menos, cinco municipalidades y por mayoría de dos tercios de los votos, que están distribuidos según la importancia demográfica de cada municipalidad.

La presidencia del consejo la asume un alcalde elegido entre alguna de las tres personas siguientes: el alcalde de la ciudad de Quebec, un alcalde representante de las ciudades de Beauport, Charlesbourg y Sainte-Foy y un alcalde representante de las municipalidades de Cap-Rouge, Lac SaintCharles, L'Ancienne-Lorette, Loretville, Saint-Augustin-de-Desmaures, Saint-Émile, Sillery, Val-Bélair y Vanier. Las otras personas que no resulten elegidas para el cargo de presidente de la comunidad urbana ostentarán la primera y la segunda vicepresidencia, formando, junto con el presidente, el comité ejecutivo que ejercerá los poderes que el consejo le delegue.

La comunidad urbana de Montreal tiene un consejo compuesto por el presidente del comité ejecutivo, el alcalde, los consejeros de la ciudad de Montreal y un delegado (el alcalde $u$ otro miembro designado por el consejo municipal) de cada una de las veintiocho municipalidades que, junto con la ciudad de Montreal, forman la comunidad urbana.

El presidente y el vicepresidente del consejo son nombrados obligatoriamente por y entre los miembros del consejo para un mandato cuya duración está establecida por el propio consejo. Uno de los dos cargos debe proceder de la ciudad de Montreal, lo que resultará fácil habida cuenta, como hemos señalado, que el alcalde y los 73 consejeros de Montreal forman parte del consejo de esta comunidad urbana, y el otro de una municipalidad de los alrededores.

La comunidad urbana de Montreal cuenta, asimismo, con un consejo ejecutivo compuesto por trece miembros designados por el consejo.

Por su parte, la comunidad urbana de Outaouais cuenta con un consejo compuesto por un presidente y dos representantes de las ciudades de Aylmer, Buckingham, Gatineau, Hull y Masson.

Las tres comunidades urbanas no tienen el mismo haz de competencias., aunque tienen algunas comunes, como la elaboración de la contribución territorial, la ordenación del territorio y la depuración de aguas. Cada comunidad urbana dispone de competencias específicas atribuidas por su ley reguladora.

La Administración regional Kativik está administrada por un consejo y un comité administrativo. El consejo está integrado por tantos consejeros 
como municipalidades integran el territorio que está al norte del paralelo 55. Los consejeros están designados por y entre los miembros de los consejos de las municipalidades, si bien debe tenerse presente que el alcalde de la municipalidad naskapi es de oficio consejero regional en el consejo de esta entidad. El consejo se ocupa, lógicamente, de los asuntos de la administración regional, mientras que el comité ejecutivo lo hace de la administración ordinaria de la entidad y de algunas funciones específicas.

La Administración regional Kativik ostenta competencias sobre administración local, policía, transportes, comunicaciones, formación profesional y empleo, etc. 